\title{
Exploring Predictors of Outcome in the Psychosis Prodrome: Implications for Early Identification and Intervention
}

\author{
Tara A. Niendam • Maria Jalbrzikowski • \\ Carrie E. Bearden
}

Received: 9 March 2009 / Accepted: 2 July 2009 /Published online: 14 July 2009

(C) The Author(s) 2009. This article is published with open access at Springerlink.com

\begin{abstract}
Functional disability is a key component of many psychiatric illnesses, particularly schizophrenia. Impairments in social and role functioning are linked to cognitive deficits, a core feature of psychosis. Retrospective analyses demonstrate that substantial functional decline precedes the onset of psychosis. Recent investigations reveal that individuals at clinical-high-risk (CHR) for psychosis show impairments in social relationships, work/school functioning and daily living skills. CHR youth also demonstrate a pattern of impairment across a range of cognitive domains, including social cognition, which is qualitatively similar to that of individuals with schizophrenia. While many studies have sought to elucidate predictors of clinical deterioration, specifically the development of schizophrenia, in such CHR samples, few have investigated factors relevant to psychosocial outcome. This review integrates recent findings regarding cognitive and social-cognitive predictors of
\end{abstract}

T. A. Niendam $(\square)$

UC Davis Department of Psychiatry \& Behavioral Sciences,

UC Davis Imaging Research Center,

4701 X Street, Suite E,

Sacramento, CA 95816, USA

e-mail: tniendam@ucdavis.edu

M. Jalbrzikowski $\cdot$ C. E. Bearden

Department of Psychology, UCLA,

Los Angeles, CA, USA

C. E. Bearden

Department of Psychiatry and Biobehavioral Sciences, UCLA,

Los Angeles, CA, USA

C. E. Bearden

Brain Research Institute, UCLA,

Los Angeles, CA, USA outcome in CHR individuals, and proposes potential directions for future research that will contribute to targeted interventions and improved outcome for at-risk youth.

Keywords Schizophrenia · Prodrome - Ultra-high-risk · Social cognition $\cdot$ Clinical high-risk $\cdot$ Psychosocial functioning $\cdot$ Functional outcome $\cdot$ Neurocognition

\section{Introduction}

The first few years of psychosis represent a critical period, as many patients show substantial cognitive and social deterioration, and some attempt suicide (Amminger et al. 2002; Larsen et al. 1996; Yung and McGorry 1996). Two recent meta-analyses have examined the relationship between duration of untreated psychosis (DUP) and outcome, finding that longer DUP was associated with worse outcome at 6 months in terms of total symptoms, overall functioning, positive symptoms, and quality of life (Marshall et al. 2005), as well as poorer response to antipsychotic treatment (Perkins et al. 2005). Consequently, in hope of decreasing the adverse impact of schizophrenia on functional outcome, many researchers have highlighted the need to intervene earlier in the development of psychosis, in the "prodromal" phase (e.g., McGlashan and Johannessen 1996). Over the past decade, researchers have used two primary methods to identify individuals as putatively prodromal for psychosis: 1) self-report of "basic symptoms," including disturbances in thought, language, perception, tolerance to stress, and socialemotional reactivity (Klosterkotter et al. 2001) or 2) the diagnosis of attenuated subthreshold psychotic symptoms, transient psychotic symptoms, or a substantial drop in social and role functioning in conjunction with genetic risk (McGlashan 2001; Miller et al. 1999). These criteria are 
thought to define individuals who are at clinical-high-risk (CHR) for developing a psychotic disorder, typically schizophrenia, within the year following identification. Early studies reported rates of conversion to psychosis in CHR samples ranging from 21\% (Yung and McGorry 1996) to 54\% (Miller et al. 2002) within the first 12 months after identification. Recently, a multi-site longitudinal study showed that $20 \%$ of individuals convert to psychosis within the first year while an additional 15\% develop psychosis in the second year of follow-up (Cannon et al. 2008), revealing a prolonged period of risk over the first two years following identification.

Although current CHR identification methods based on clinical symptomatology allow researchers to identify and intervene earlier with individuals who are at increased clinical risk for developing psychosis, use of these criteria alone yields low to moderate predictive power $(12 \%-70 \%)$ for determining exactly which individuals will be diagnosed subsequently with a psychotic disorder (Klosterkotter et al. 2001; Yung et al. 2005). The inclusion of additional clinical criteria using multivariate prediction algorithms can improve the predictive power to approximately $80 \%$ (Cannon et al. 2008) although sensitivity of this model for detecting truly at-risk cases remained low. Cognitive phenotypes may serve as additional predictors to enhance our ability to identify those individuals at greatest risk for imminent clinical deterioration (Brewer et al. 2006; Wood et al. 2008). Cognitive functions are important, not only as a window into the pathophysiology of the development of psychotic illness, but also because they are strongly associated with functional outcome (Green 1996; Green et al. 2000). Substantial functional impairment occurs early in the course of illness and likely sets the stage for later social and occupational dysfunction (Malla and Payne 2005). Therefore, the prediction of psychosocial outcome represents an associated line of research that is essential for the enhancement of appropriate early intervention techniques. This review explores our current understanding of relationships between cognition, social cognition, and outcome in CHR individuals and proposes potential areas of research that will contribute to targeted intervention and improved outcome for at-risk youth.

\section{Onset of Schizophrenia: A Neurodevelopmental View}

To develop better methods of prediction and understand how cognition is related to functional outcome in schizophrenia, it is important to examine the neurodevelopmental pathways that are believed to contribute to the onset of schizophrenia. Though the onset of schizophrenia does not usually occur until adolescence or early adulthood, there are a host of pre-, peri-, and postnatal developmental periods that are believed to contribute to an increased risk for developing schizophrenia. As illustrated in Fig. 1, a number of vulnerability-related and progressive neuroanatomic abnormalities are hypothesized to contribute to the manifestation of clinical symptoms, cognitive impairment, and psychosocial dysfunction associated with progression toward psychosis in at-risk individuals. For example, it has been shown that hypoxic complications during birth predict increased gray matter loss in those who develop schizophrenia (Cannon et al. 2002). During early development, it is hypothesized that early brain vulnerabilities such as reduced synaptic plasticity (Friston 1998), hippocampal dysgenesis (Wood et al. 1997), and/or disruption of white matter integrity (Davis et al. 2003) may affect later developmental processes in the brain. These brain processes, such as aberrant synaptic pruning (McGlashan and Hoffman 2000) peak during adolescence and are hypothesized to contribute to the onset of schizophrenia, and the 'disconnectivity' that appears characteristic of the disorder (Friston 1998). Various environmental triggers may interact with these brain changes, as epidemiological evidence suggests that social stress and/or early substance use may precipitate the onset of the disorder (Bebbington et al. 1993; Sugranyes et al. 2009).

Ultimately, the progressive white and gray matter changes that take place during adolescence may have a large impact on the brain dysfunction seen in the prodromal phase of psychosis. For instance, it has been shown that those CHR individuals who go on to develop schizophrenia show differential gray matter loss over one year, relative to those who do not develop psychosis (Sun et al. 2009). While the etiology of the observed changes in brain structure is unknown, such abnormalities likely contribute to the expression of cognitive deficits in a variety of domains, including social cognition, that are observed in those with established illness (e.g., Pinkham and Penn 2006; Yoon et al. 2008). Deterioration in cognitive functions may accelerate during the prodromal period, in association with changes in brain functioning that lead to the development of overt psychotic symptoms (Feinberg 1982; McGlashan and Hoffman 2000). Such changes may also lead to functional decline in a variety of domains (Cosway et al. 2000). Therefore, deficits in cognition in high-risk samples not only serve as stable markers of risk, but progression of such deficits over time may differentiate those individuals who experience clinical and functional deterioration from those who do not.

\section{Cognition and Functional Outcome}

Before we explore the pattern of cognitive impairment observed in CHR individuals, it is important to understand 


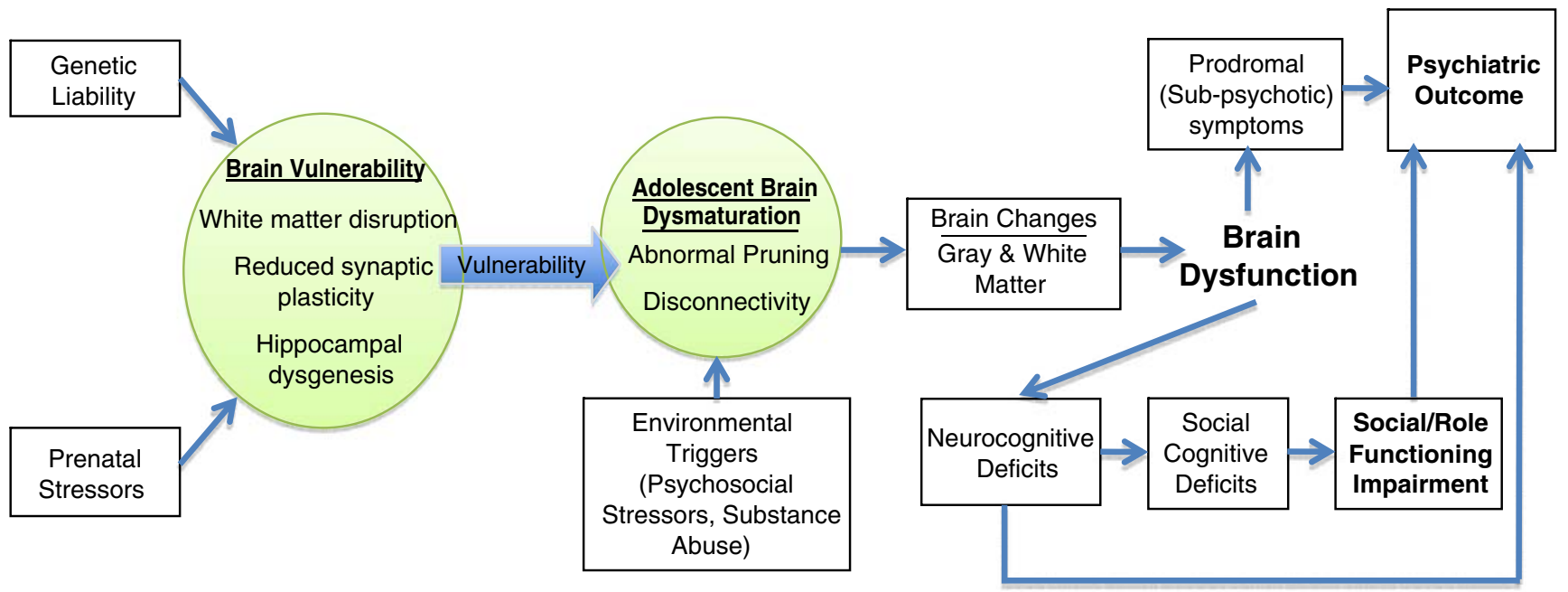

DEVELOPMENTAL Birth $\begin{aligned} & \text { Childhood/ } \\ & \text { Premorbid }\end{aligned}$
PERIOD

Prodromal

Outcome

Fig. 1 Conceptual model of vulnerability-related and progressive neuroanatomic abnormalities associated with cognitive impairment and functional outcome in individuals at risk for psychosis

the close inter-relationship between cognition and outcome in patients with established schizophrenia. Cognitive impairment has been identified a core feature of the disorder since its earliest descriptions (Bleuler 1950; Kraeplin 1896). Within the domain of higher-order cognitive functions, disturbances have been described in the domains of selective attention (Carter et al. 1992; Cornblatt et al. 1989; Mirsky 1969; Nuechterlein and Dawson 1984), working memory (Carter et al. 1996; Glahn et al. 2000; Gold et al. 1997; Keefe et al. 1995; Park and Holzman 1992), episodic memory (Clare et al. 1993; Ranganath et al. 2008; Saykin et al. 1991; Schwartz et al. 1992; Tamlyn et al. 1992), language production (Barch and Berenbaum 1996; Docherty et al. 1996; Docherty et al. 1988; Harvey 1983) and comprehension (Condray et al. 1995; Morice and McNicol 1985). This wide variety of cognitive impairments are hypothesized to reflect underlying anomalies in brain function and structure (e.g., Honey et al. 2005; Jafri et al. 2008; Kim et al. 2009; Liang et al. 2006; Liu et al. 2008; Schlosser et al. 2003). For example, it has been suggested that widespread anomalies in neurotransmitter systems, such as dysfunction of NMDA (N-methyl-D-aspartate) receptor-mediated neurotransmission, or reductions in neuropil, the dense network of brain tissue that lies between axons, may contribute to the pervasive pattern of cognitive dysfunction seen in the disorder (Javitt and Zukin 1991; Selemon and Goldman-Rakic 1999).

Cognitive dysfunction in schizophrenia, which is believed to reflect underlying disturbance in neural systems, has been consistently associated with poor outcome in work, school, and social domains (Green 1996; Green et al. 2000). More recently, Green and Nuechterlein (2004) found that cognition can reliably predict long-term outcome in schizophrenia, with medium to large effect sizes ( $0.5-0.8$ or higher) reported for 16 longitudinal studies that were reviewed. Additionally, there is evidence suggesting that structural brain changes, such as greater ventricular enlargement, are associated with poorer clinical outcome in schizophrenia patients (Ho et al. 2003; Lieberman et al. 2001). Others have found that, in first-episode schizophrenia patients, decreased volume in the dorsolateral prefrontal cortex at baseline predicted functional outcome at a one year followup (Prasad et al. 2005). Although these studies suggest potential for the ability of neurobiological indices to predict functional outcome, they have not yet been replicated and do not appear to show as strong a predictive relationship to outcome as cognitive measures. In addition, some studies have failed to find a relationship between longitudinal brain changes and functional outcome in patients with schizophrenia (e.g., Milev et al. 2003; van Haren et al. 2003). As such, is it important to explore whether at-risk individuals show similar relationships between cognitive and neuralsystems dysfunction and outcome.

Though cognitive deficits are evident years before the development of overt psychotic symptoms, during early childhood and adolescence (Cannon et al. 2000; Cornblatt et al. 1999; Erlenmeyer-Kimling et al. 2000; Jones et al. 1994; Niendam et al. 2003; Russell et al. 1997), additional cognitive deterioration is likely to occur during the prodromal phase or at illness onset (Bilder et al. 2006; Fuller et al. 2002). Impairments in multiple cognitive domains have been observed in CHR patients relative to 
demographically similar controls, including sustained attention, working memory, processing speed, executive functioning, and verbal learning and memory (Bartok et al. 2005; Brewer et al. 2005; Eastvold et al. 2007; Francey et al. 2005; Gschwandtner et al. 2003; Gschwandtner et al. 2006; Hambrecht et al. 2002; Hawkins et al. 2004; Keefe et al. 2006; Lencz et al. 2006; Niendam et al. 2006; Niendam et al. 2007; Pukrop et al. 2007; Pukrop et al. 2006; Silverstein et al. 2006; Simon et al. 2007; Smith et al. 2006; Wood et al. 2003). Neverthless, CHR individualson average - tend to show better performance than individuals in their first-episode of schizophrenia (Hambrecht et al. 2002; Hawkins et al. 2004; Keefe et al. 2006), further supporting the notion that there may be some cognitive deterioration associated with onset of overt illness. Additionally, there is evidence that progressive changes in cognitive measures may distinguish those who go on to develop full-blown illness from those who do not. In particular, impairments on neuropsychological measures of prefrontal cognitive functioning, including spatial working memory (Wood et al. 2003), antisaccade eye movements (Nieman et al. 2007), olfactory identification (Brewer et al. 2003), and rapid information processing (Brewer et al. 2005; Lencz et al. 2006) have been associated with conversion to psychosis in CHR individuals.

While a number of studies have examined cognitive predictors of clinical outcome (i.e., conversion to psychosis), the relationship between cognition and psychosocial outcome has received little exploration in CHR samples. The few existing studies support a relationship between cognition, clinical symptoms, and psychosocial functioning in CHR populations (Niendam et al. 2006; Niendam et al. 2007). In particular, Niendam et al. (2006) found that baseline verbal memory deficits in CHR individuals were significantly associated with poorer social functioning. A trend association between poorer reasoning and problem solving and poorer global functioning was also detected. Additionally, verbal memory impairment was associated with poorer social functioning and higher rates of negative symptoms in CHR individuals, independent of positive symptom severity. When cognition and psychosocial functioning were examined over an average follow-up period of eight months (Niendam et al. 2007), improvement in psychosocial functioning was observed in a subset of CHR individuals, and this change was associated with improvement in cognition and clinical symptoms. Specifically, improvement in social functioning was associated with significant improvement in both processing speed and visual learning and memory at follow-up. Finally, reduction in both positive and negative symptoms was associated with improvement in social and role functioning, respectively. These findings suggest that the pattern of cognitive change over time may differentiate those CHR individuals who will go on to experience good versus poor functional outcome.

\section{Progressive Brain Changes and Outcome in Early Psychosis}

Given the observed similarity in patterns of cognitive impairment between schizophrenia patients and those at risk for the illness, investigators have begun to examine the neural substrates of cognitive dysfunction in CHR youth and their relationship to clinical and functional outcome. In typically developing adolescents, gray matter loss is paralleled by an increase in white matter (Giedd et al. 1999; Gogtay et al. 2004; Paus et al. 2001), and these changes mediate the continued development of cognition (Casey et al. 2000). Many of the findings of changes in brain structure and function in CHR individuals are consistent with the notion that the pathophysiology of schizophrenia involves an exacerbation of normal adolescent brain developmental processes, such as synaptic pruning, that result in disrupted neural connectivity (Karlsgodt et al. 2008; McGlashan and Hoffman 2000). Relative to healthy controls, CHR individuals demonstrate a variety of structural and functional brain abnormalities that are generally consistent with findings in first-episode schizophrenia [for review see Karlsgodt et al. 2008; McGlashan and Hoffman 2000; Wood et al. 2008]. Recent neuroimaging studies show that CHR individuals have widespread reductions in gray matter density in a variety of brain regions, including the anterior cingulate, hippocampus, and medial temporal brain regions (Borgwardt et al. 2007b; Hurlemann et al. 2008; Pantelis et al. 2003; Phillips et al. 2002; Wood et al. 2005). Structural neuroimaging studies have also shown that reduced gray matter density in frontal, temporal and parietal regions at baseline is associated with subsequent conversion to psychosis (Borgwardt et al. 2008; Borgwardt et al. 2007a; Fornito et al. 2008; Pantelis et al. 2003; Pantelis et al. 2005).

In particular, changes in gray matter over time may serve as a marker for increased risk for conversion. Sun et al. (2009) found that CHR youth who converted to psychosis showed a significantly greater rate of brain surface contraction in right prefrontal regions when compared directly with nonconverters. In addition, the brain surface contractions in the converters resembled the patterns found in first-episode schizophrenia patients in another longitudinal MRI study analyzed using the same methods (Sun et al. 2008). In this study, first-episode patients showed a significantly steeper rate of gray matter reduction than healthy subjects, but in the same regions that healthy subjects showed maturation-related decline. Others have found that, in comparison to CHR individuals who do not 
develop psychosis, CHR individuals who go on to develop psychosis show greater gray matter decrements in the insular cortex at baseline (Takahashi et al. 2009). Additionally, Job et al. (2006) found that gray matter change in the inferior temporal gyrus had a $60 \%$ positive predictive value for the development of schizophrenia (likelihood ratio $>10$ ) in individuals at genetic risk for psychosis (by virtue of having an affected parent),as compared to $13 \%$ risk in the cohort overall 1. Finally, initial evidence suggests that a longer prodromal phase prior to the onset of psychosis, measured retrospectively through interviews and chart review, is associated with smaller gray matter volumes in the cingulate, frontal and left insular cortex (Lappin et al. 2007). These findings suggest that the incorporation of longitudinal measures of gray matter change with other clinical and cognitive measures may improve our predictive power for detecting those at highest risk for schizophrenia. To our knowledge, no studies have yet attempted to combine neurobiological measures with clinical predictors in order to improve prediction of outcome.

Abnormalities in white matter connectivity have also been reported in CHR samples. Reductions in temporal white matter, as measured by voxel-based morphometry, have been observed in CHR samples (Witthaus et al. 2008). Preliminary data also suggests that individuals who experienced a longer prodromal period prior to developing schizophrenia (measured retrospectively) had less white matter volume bilaterally in the superior longitudinal and uncinate fasciculi and the cingulum than those with a shorter prodromal phase (Lappin et al. 2007). Additionally, when comparing CHR males to healthy controls in a diffusion tensor imaging (DTI) study, CHR males showed reduced white matter integrity, as measured by fractional anisotropy (FA), in right superior and left middle frontal regions (Peters et al. 2009). When examining white matter alterations using structural magnetic resonance imaging (MRI) in CHR individuals over a $12-18$ month follow-up period, Walterfang et al. (2008a) found a baseline reduction in volume in the region of the fronto-occipital fasciculus, a white matter tract connecting the frontal cortex with the temporal, parietal and occipital cortices of the same hemisphere, in CHR individuals who subsequently developed psychosis. Reduced thickness of the genu of the corpus callosum (Walterfang et al. 2008b) has also been associated with subsequent conversion.

To date, the relationship between these brain abnormalities and functional outcome in CHR individuals has only been examined in one study. A preliminary investigation of the relationship between white matter integrity, and functional outcome over time in CHR youth revealed robust effect sizes (ranging from 1.26 to 1.94), showing that lower baseline measures of FA in the medial temporal lobe and inferior longitudinal fasciculus, the major white matter tract connecting temporal and occipital lobes, predicted deterioration in social and role functioning in CHR participants at 15-month follow-up (Karlsgodt et al. 2009).

\section{Social Cognition and Functional Outcome in Schizophrenia and At-Risk Individuals}

Although a large body of research supports a connection between cognition and functional outcome in schizophrenia, standard cognitive measures appear to account for only a small portion of the variance in functional outcome in affected individuals (Holthausen et al. 2003; Penn et al. 1997). In most studies the variance accounted for by composite measures of neurocognition ranged from $20 \%$ to $40 \%$, suggesting that the majority of the variance in functional outcome is unaccounted for by traditional neurocognitive measures (Couture et al. 2006). Researchers have suggested that this relationship may be explained by a third variable, social cognition (Green et al. 2000; Sergi et al. 2007). Social cognition can be defined as the mental processes by which humans perceive and think about themselves, and how they interpret and respond to others' behavior (Adolphs 2001). Social cognition impairments in schizophrenia are correlated with a variety of basic cognitive deficits, such as verbal memory (Brune 2005) and executive functioning (Bryson et al. 1997), with 'basic neurocognition' referring to primary cognitive, nonemotive processes such as encoding, retrieval, and attention. However, structural equation modeling and factor analyses have revealed that basic neurocognition and social cognition are best explained as separate, but related, constructs (Allen et al. 2007; Sergi et al. 2007). Additionally, because it is believed that schizophrenia is a disorder with widespread brain dysfunction between connecting regions, it is important to examine a construct that taps into these various areas, such as social cognition (Frith and Frith 2007).

In comparison to basic neurocognition, laboratory-based measures of social cognition have been shown to be better predictors of community functioning (Pijnenborg et al. 2009), more closely associated with social functioning (Roncone et al. 2002), and stronger predictors of social behavioral problems in schizophrenia patients (Brune et al. 2007). Furthermore, modeling analyses have shown that social cognition is a mediator between basic neurocognition and functional outcome in schizophrenia (Brekke et al. 2005; Sergi et al. 2006; Vauth et al. 2004), providing the strongest evidence that social cognition explains the relationship between these two domains.

A large body of research documents the deficits in social cognition associated with schizophrenia: ranging from deficits in theory of mind (ToM) [for a review, see (Bora 
et al. 2009)], which assesses one's ability to comprehend the intentions of others (Frith 1992), to deficits in social perception and social knowledge, both of which refer to the ability to use social cues (e.g., gestures) and apply social rules to a complicated situation (Penn et al. 2002; Sergi et al. 2009_-see Table 1 for more information). When examining social cognition and its relationship to functional outcome in schizophrenia, strong, consistent relationships between the two have been identified [for a review, see (Couture et al. 2006)]. For example, Couture et al. (2006) found that, for the majority $(82 \%)$ of the studies examined, there were moderate to large effect sizes $(0.5-0.8)$ for the relationship between social cognition measures and functional outcome. ToM deficits in schizophrenia have been correlated with poorer childhood social functioning, earlier age of onset of illness (Schenkel et al. 2005) and poor current social functioning in schizophrenia patients (Bora et al. 2006; Brune 2005). Deficits in social knowledge and social perception have been linked to poorer social functioning (Addington et al. 2006). At the same time, greater social knowledge is associated with better interpersonal skills in schizophrenia patients (Pinkham and Penn 2006). Finally, emotion processing deficits in schizophrenia patients, assessed using facial emotion recognition tasks, such as the Face Emotion Identification Task (Kerr and Neale 1993) are associated - in cross-sectional studies- with lower concurrent community functioning (Kee et al. 2009), decreased levels of role functioning (Eack et al. 2008), decreased ability to live independently and function at work (Kee et al. 2003), and decreased interpersonal skills (Pinkham and Penn 2006). Despite demonstrated impairment across multiple domains of social cognition in schizophrenia, rarely are these constructs examined concurrently. Further research exploring the independence of or overlap between these constructs is necessary to develop more efficient assessment and diagnostic tools for schizophrenia patients.

Although social cognition has been extensively examined in schizophrenia, only a few studies have looked at directly at aspects of social cognition in CHR samples. Like their same-age peers, CHR individuals are likely to be going through adolescence or young adulthood, critical periods related to the development of one's identity and understanding oneself in relation to others (Blakemore and Choudhury 2006). During adolescence, young people become more concerned with how they are seen by others, become more independent in their decision-making processes, and experience important developmental shifts in relationships. This increased importance of social interactions during adolescence underscores the importance of looking at changes and development of social cognition in CHR individuals and its impact on clinical and functional outcome.

It is hypothesized that developmental precursors during adolescence, such as how an individual attends to social information, may be impaired in CHR individuals, leading to difficulties in interpersonal relationships and social interactions (Cornblatt et al. 1999). Investigations of social cognition in CHR individuals have found deficits in ToM tasks (Chung et al. 2008), as assessed by the False Belief Task (Perner and Wimmer 1985; Wimmer and Perner 1983) and the Strange Story Task (Happe 1994), both of which test one's ability to make inferences about a character's mental state. Using Kerr and Neale's (1993) measures of facial emotion identification and emotion discrimination, Addington et al. (2008) observed emotion recognition deficits in CHR individuals, suggesting that emotion processing deficits exist prior to the onset of illness. Additionally, 25\% of CHR adolescents seeking treatment reported a decreased ability to discriminate between different emotions (Hambrecht et al. 2002). However, findings are not consistent across studies, as others who used the same measures have found emotion processing to be intact in CHR individuals (Pinkham et al. 2007). Furthermore, a recent study comparing healthy adolescent controls to those with adolescent-onset schizophrenia spectrum disorders did not find significant differences in emotion processing (Holmen et al. 2009). However, the authors argued that the emotion processing test used, the Mayer-Salovey-Caruso Emotional Intelligence Test (Mayer et al. 2003) may not be appropriate for adolescents, as normative values for adolescents have not yet been established on this test (Holmen et al. 2009). This study highlights the need for more reliable and age-appropriate measures of social cognition to accurately delineate social cognition deficits in CHR individuals.

To date, no studies of CHR youth to date have explored the relevance of social cognitive deficits to concurrent clinical or psychosocial functioning or subsequent outcome. To better understand the role of social cognition in at-risk samples and thereby improve early intervention strategies in this population, it is necessary to parse out particular social cognition deficits that may exist in CHR individuals. As CHR individuals are experiencing important developmental shifts in interpersonal relationships that are common during this developmental period (Blakemore and Choudhury 2006), the investigation of social cognition in CHR individuals may represent a unique entry point for the exploration of factors that contribute to poor psychosocial functioning observed during the prodromal period (Cannon et al. 2008; Cornblatt et al. 2007) as well as the identification of specific social cognitive deficits that increase risk for subsequent conversion to schizophrenia.

\section{Conclusions and Future Directions}

Impairment in a variety of cognitive processes, including social cognition, is consistently associated with poor 
Table 1 Descriptions of the five domains of social cognition, including common measures of each domain and effect sizes (ES) for relevant findings in schizophrenia (SZ), clinical-high-risk (CHR), and control (CTL) samples

\begin{tabular}{|c|c|c|c|c|}
\hline Domain & Common Measure & Description & Group Difference Findings & Relationship To Functioning \\
\hline $\begin{array}{l}\text { Theory of Mind (ToM): } \\
\text { ability to comprehend } \\
\text { the intentions of others }\end{array}$ & $\begin{array}{l}\text { False Belief Task } \\
\text { (Perner and } \\
\text { Wimmer 1985; } \\
\text { Wimmer and } \\
\text { Perner 1983) }\end{array}$ & $\begin{array}{l}\text { Participants are given 1) a first } \\
\text { order task where they are } \\
\text { asked about their ability to } \\
\text { understand the belief of } \\
\text { another person and 2) a }\end{array}$ & $\begin{array}{l}\text { SZ }<\text { CTL in second-order, } \\
\text { but not first-order tasks; } \\
\text { ES }=1.61 \text { (Pickup and Frith } \\
2001 \text { ) } \\
\text { CHR }<\text { CTL on second }\end{array}$ & $\begin{array}{l}\text { SZ: no studies to date } \\
\text { showing the relationship } \\
\text { between this task and } \\
\text { outcome } \\
\text { CHR: no studies to date }\end{array}$ \\
\hline
\end{tabular}

second order task where they order tasks $(\mathrm{ES}=.55)$; are asked about their ability to understand someone else's belief about what a third person is thinking

Social Knowledge: ability to comprehend and apply social rules to various situations ability to use social cues (e.g., gestures) to understand complicated or ambiguous situations

\section{Schema Component Sequencing Task [SCST; (Corrigan and Toomey 1995)]}

\section{Profile of Nonverbal Sensitivity [PONS; (Rosenthal et al. 1979)]}

\begin{abstract}
Attributional Style: manner of determining the cause of a personally significant event (i.e., to the self, others, situational factors)
\end{abstract}

Emotion Processing: ability to identify or discriminate between different emotions
Participants are given different cards depicting the various components of a social situation and are instructed to arrange the cards in the correct order

$$
\begin{aligned}
& \text { Participants are presented } \\
& \text { with } 2 \text { second vignettes of a } \\
& \text { Caucasian female's bodily } \\
& \text { gestures, voice intonations, } \\
& \text { and/or facial expressions; } \\
& \text { participants must then } \\
& \text { choose an appropriate } \\
& \text { situation when this social } \\
& \text { cue would be seen }
\end{aligned}
$$

\section{Participants fill out a} questionnaire that examines their causal attributions to hypothetical social situations
$\mathrm{CHR}=\mathrm{CTL}$ on first-order tasks (Chung et al. 2008)

SZ $<$ CTL $; \mathrm{ES}=.69$

(Pinkham and Penn 2006)

CHR: No studies to date

SZ < CTL $; \mathrm{ES}=.62$

(Toomey et al. 1997)

CHR: No studies to date

\section{SZ: social knowledge significantly correlated with inter-personal skill; $\mathrm{ES}=.88$ (Pinkham and Penn 2006) \\ CHR: no studies to date}

\section{SZ: social perception} significantly correlated with social problem solving; ES ranged from . .50-.52 (Toomey et al. 1997)

CHR: no studies to date
Internal, Personal, and Situational Attributions Questionnaire [IPSAQ;

(Kinderman and Bentall 1996)]

\footnotetext{
SZ: vs. controls and patients without persecutory delusions, SZ patients with persecutory delusions were more likely to blame others rather than themselves for negative outcomes to situations; $\mathrm{ES}=.36$ (Martin and Penn 2002)

CHR: No studies to date

SZ: patients who were more likely to blame others rather than themselves for negative outcomes to situations had greater psychopathology on the PANSS; ES $=.90$ (Mizrahi et al. 2008)

CHR: no studies to date

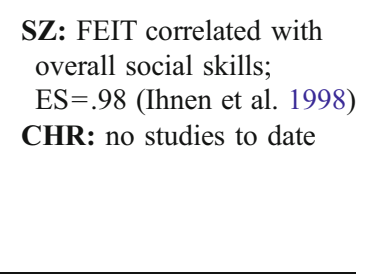

Facial Emotion Participants are presented Identification Test [FEIT; (Kerr and Neale 1993)]
Participants are presented $\quad$ SZ $<$ CTL; ES $=1.4$ (Kerr with 19 faces showing one of six emotions; after seeing each face, participants must then choose the emotion shown from six different options and Neale 1993); $\mathbf{S Z}<$ CHR < CTL; ES for SZ (multi-episode) $<\mathrm{CHR}=.23$; ES for $\mathrm{CHR}<\mathrm{CTL}=.77$, (Addington et al. 2008)

psychosocial outcome in schizophrenia (Green 1996; Green et al. 2000). Such cognitive impairments are apparent prior to illness onset, during early childhood, and associated with genetic liability for the disorder, suggesting that these deficits represent potential markers of risk for both clinical and psychosocial deterioration. In an effort to improve outcomes for those at highest risk for schizophrenia, research has turned its attention to those individuals who are beginning to show early warning signs of the illness, with the hope of providing early intervention. While many studies have investigated potential predictors of poor clinical outcome in CHR populations, including the development of schizophrenia, few have sought to elucidate predictors of poor functional outcome. While a proportion of these putative CHR or 'prodromal' individuals do not go on to develop psychosis (Cannon et al. 2008; Yung et al. 2003), nevertheless they typically experience significant psychological difficulties (Meyer et al. 2005) and marked 
impairment in psychosocial functioning (Cannon et al. 2008; Cornblatt et al. 2007). This review seeks to encourage the investigation of predictors of psychosocial outcome in such at risk samples in order to refine early intervention strategies.

To reach this goal, the field needs to address three important issues. First, the development of age-appropriate measures of psychosocial functioning is required to adequately explore the effects of cognition on outcome in younger samples. Multi-site collaborations have yielded new measures of global social and role functioning for use in younger populations (Cornblatt et al. 2007) which are sensitive to the functional consequences of cognitive impairment in CHR youth (Niendam et al. 2006, 2007). However, these global measures do not permit fine-grained analysis of specific domains of psychosocial functioning, such as everyday interpersonal skills.

Second, although social cognition is increasingly recognized as an important contributor to outcome in patients with schizophrenia, existing measures of social cognition may not be sensitive to the impairments that are present in younger populations (Holmen et al. 2009). Additionally, to explore whether the same domains of social cognition parse out as unique constructs in CHR individuals, it is important to assess multiple aspects of social cognition in this population. To ensure that investigators assess clinically relevant aspects of social cognitive function over time, research should explore the magnitude and developmental time course of impairment across these domains of social cognition in CHR individuals. Results of these investigations will allow development of interventions that target the most critical areas of deficit. Enhancing specificity of early intervention targets in these individuals may result in a less severe course of illness.

Third, the exploration of relationships between neurocognition, social cognition, and psychosocial functioning must consider the dynamic changes that occur during adolescence into young adulthood. Many previous studies sought to identify factors at baseline that would predict subsequent clinical or psychosocial deterioration. Given the myriad of changes that occur during development in CHR individuals, future investigations should seek to examine how changes in cognition are associated with changes in functioning over time, in order to determine if risk for deterioration is more closely associated with dynamic changes over time, rather than baseline cognitive functioning.

By focusing our investigations on factors that contribute to both clinical and functional deterioration in at-risk samples, we will be able to enhance our methods of early identification and develop targeted, cost-effective treatments that address the deficits that contribute to future disability. The field has shifted to the identification of specific cognitive targets for remediation in an effort to improve cognition and long-term outcome in schizophrenia (Gold 2004; Green and Nuechterlein 2004; McKibbin et al. 2004) and preliminary results have shown potential. For example, a meta-analysis examining the effects of cognitive remediation on cognition and outcome found that both cognition (effect size: 0.41) and psychosocial functioning (effect size: 0.38) significantly improved with cognitive remediation treatment (McGurk et al. 2007). Moreover, cognitive remediation programs that were paired with psychiatric rehabilitation showed greater improvement in functional outcome (effect size: 0.47 ) than programs that did not have this adjunct treatment (effect size: 0.05). Recent findings suggest that impairments in speeded information-processing and learning and memory functions are associated with poorer psychosocial functioning in CHR youth (Niendam et al. 2006; Niendam et al. 2007). While neuroimaging evidence suggests that these cognitive deficits are likely associated with brain-based developmental changes, it is unclear whether interventions targeting the specific brain mechanism, via medication or cognitive remediation training, or psychosocial interventions targeting specific domains of functioning, such as individual, group or family therapy, could also serve to improve clinical or functional outcome in at risk youth.

Additionally, specific treatment programs designed to address social cognition in schizophrenia (Penn et al. 2007) have shown positive results and may hold promise for atrisk populations. For example, schizophrenia inpatients who participated in the Social Cognition and Interaction Training program (SCIT) showed improvement on multiple measures of social cognition, showed less aggressive behavior on hospital wards, and had more social relationships at post-test (Combs et al. 2007). Others, using a program known as the Tackling Affect Recognition [TAR, (Wolwer et al. 2005)], found that schizophrenia patients' emotional recognition abilities improved with use of this program; however, these investigators did not see this improvement when the schizophrenia patients were only given a cognitive remediation program, suggesting that these programs may target deficits that basic cognitive remediation programs do not (Frommann et al. 2003). Outpatients with schizophrenia have also shown improvement in facial affect recognition after receiving a program combining components of the SCIT and of the TAR (Horan et al. 2009). However, these types of remediation programs have not yet been applied in at-risk populations.

While the few existing placebo controlled pharmacologic treatment studies in treatment-seeking CHR individuals have generally found reduced rates of conversion to psychosis in the active treatment group (e.g., McGlashan et al. 2006; McGorry et al. 2002), very few studies have examined functional outcome as an endpoint. In a randomized, double-blind study comparing olanzapine to placebo, 
McGlashan et al. (2006) did not find significant differences in global assessment of functioning (GAF) score changes over the course of a year. Additionally, a study comparing needsbased interventions with a combined low dose risperidone treatment and cognitive behavioral therapy did not find significant differences between the two groups' GAF scores at the 12 month follow-up (McGorry et al. 2002). While no significant improvement in global functioning was observed with medication in these CHR studies, the use of more specific and age-appropriate measures of social and role functioning may have served to elucidate small changes in functioning that were associated with treatment.

In summary, investigation of clinical and neurobiological predictors of functional outcome in youth at clinical high risk for psychosis is in its very early stages. One of the current challenges in the field is to apply multivariate algorithms to better determine whether positive predictive power is improved by including measures of neurocognition, social cognition and/or neuroanatomy in the same predictive algorithm as clinical measures. To date, clinical and neurobiological markers have not been simultaneously investigated as predictors in the same study. These types of analyses are currently underway in large, multi-site studies of youth at clinical high risk for psychosis. Findings will set the stage for targeted interventions that can be applied to those at greatest risk for illness and long-term functional impairment.

Acknowledgments This research was supported by National Institutes of Health (NIH) Grants MH65079, MH066286, GM072978, and RR02199; MH14584 to TAN; the National Alliance for Research on Schizophrenia and Affective Disorders to CEB; and a gift to the University of California, Los Angeles (UCLA) Foundation by Garen and Shari Staglin.

Disclosures The authors have no conflicts of interest to report.

Open Access This article is distributed under the terms of the Creative Commons Attribution Noncommercial License which permits any noncommercial use, distribution, and reproduction in any medium, provided the original author(s) and source are credited.

\section{References}

Addington, J., Saeedi, H., \& Addington, D. (2006). Influence of social perception and social knowledge on cognitive and social functioning in early psychosis. British Journal of Psychiatry, 189, 373-378.

Addington, J., Penn, D., Woods, S. W., Addington, D., \& Perkins, D. O. (2008). Facial affect recognition in individuals at clinical high risk for psychosis. British Journal of Psychiatry, 192(1), 67-68.

Adolphs, R. (2001). The neurobiology of social cognition. Current Opinion in Neurobiology, 11(2), 231-239.

Allen, D. N., Strauss, G. P., Donohue, B., \& van Kammen, D. P. (2007). Factor analytic support for social cognition as a separable cognitive domain in schizophrenia. Schizophrenia Research, 93 (1-3), 325-333.
Amminger, G. P., Edwards, J., Brewer, W. J., Harrigan, S., \& McGorry, P. D. (2002). Duration of untreated psychosis and cognitive deterioration in first-episode schizophrenia. Schizophrenia Research, 54(3), 223-230.

Barch, D. M., \& Berenbaum, H. (1996). Language production and thought disorder in schizophrenia. Journal of Abnormal Psychology, 105(1), 81-88.

Bartok, E., Berecz, R., Glaub, T., \& Degrell, I. (2005). Cognitive functions in prepsychotic patients. Progress in Neuropsychopharmacology and Biological Psychiatry, 29(4), 621-625.

Bebbington, P., Wilkins, S., Jones, P., Foerster, A., Murray, R., Toone, B., et al. (1993). Life events and psychosis. Initial results from the Camberwell Collaborative Psychosis Study. British Journal of Psychiatry, 162, 72-79.

Bilder, R. M., Reiter, G., Bates, J., Lencz, T., Szeszko, P., Goldman, R. S., et al. (2006). Cognitive development in schizophrenia: follow-back from the first episode. Journal of Clinical and Experimental Neuropsychology, 28(2), 270-282.

Blakemore, S. J., \& Choudhury, S. (2006). Development of the adolescent brain: implications for executive function and social cognition. Journal of Child Psychology and Psychiatry, 47(3-4), 296-312.

Bleuler, E. (1950). Dementia praecox or the group of schizophren ias (T. B. J. Zinklin, Trans.). New York: International Universities Press (Original work published in 1911).

Bora, E., Eryavuz, A., Kayahan, B., Sungu, G., \& Veznedaroglu, B. (2006). Social functioning, theory of mind and neurocognition in outpatients with schizophrenia; mental state decoding may be a better predictor of social functioning than mental state reasoning. Psychiatry Research, 145(2-3), 95-103.

Bora, E., Yucel, M., \& Pantelis, C. (2009). Theory of mind impairment in schizophrenia: Meta-analysis. Schizophrenia Research, doi:10.1016/j.schres.2008.1012.1020.

Borgwardt, S. J., McGuire, P., Fusar-Poli, P., Radue, E. W., \& Riecher-Rossler, A. (2008). Anterior cingulate pathology in the prodromal stage of schizophrenia. Neuroimage, 39(2), 553-554.

Borgwardt, S. J., McGuire, P. K., Aston, J., Berger, G., Dazzan, P., Gschwandtner, U., et al. (2007). Structural brain abnormalities in individuals with an at-risk mental state who later develop psychosis. British Journal of Psychiatry Supplement, 51, s69-75.

Borgwardt, S. J., Riecher-Rossler, A., Dazzan, P., Chitnis, X., Aston, J., Drewe, M., et al. (2007). Regional gray matter volume abnormalities in the at risk mental state. Biological Psychiatry, 61 (10), 1148-1156.

Brekke, J. S., Kay, D. D., Lee, K. S., \& Green, M. F. (2005). Biosocial pathways to functional outcome in schizophrenia. Schizophrenia Research, 80(2-3), 213-225.

Brewer, W. J., Francey, S. M., Wood, S. J., Jackson, H. J., Pantelis, C., Phillips, L. J., et al. (2005). Memory impairments identified in people at ultra-high risk for psychosis who later develop firstepisode psychosis. American Journal of Psychiatry, 162(1), 71-78.

Brewer, W. J., Wood, S. J., McGorry, P. D., Francey, S. M., Phillips, L. J., Yung, A. R., et al. (2003). Impairment of olfactory identification ability in individuals at ultra-high risk for psychosis who later develop schizophrenia. American Journal of Psychiatry, 160(10), 1790-1794.

Brewer, W. J., Wood, S. J., Phillips, L. J., Francey, S. M., Pantelis, C., Yung, A. R., et al. (2006). Generalized and specific cognitive performance in clinical high-risk cohorts: a review highlighting potential vulnerability markers for psychosis. Schizophrenia Bulletin, 32(3), 538-555.

Brune, M. (2005). Emotion recognition, 'theory of mind', and social behavior in schizophrenia. Psychiatry Research, 133(2-3), 135-147.

Brune, M., Abdel-Hamid, M., Lehmkamper, C., \& Sonntag, C. (2007). Mental state attribution, neurocognitive functioning, and 
psychopathology: what predicts poor social competence in schizophrenia best? Schizophrenia Research, 92(1-3), 151-159.

Bryson, G., Bell, M., \& Lysaker, P. (1997). Affect recognition in schizophrenia: a function of global impairment or a specific cognitive deficit. Psychiatry Research, 71(2), 105-113.

Cannon, T. D., Bearden, C. E., Hollister, J. M., Rosso, I. M., Sanchez, L. E., \& Hadley, T. (2000). Childhood cognitive functioning in schizophrenia patients and their unaffected siblings: a prospective cohort study. Schizophrenia Bulletin, 26(2), 379-393.

Cannon, T. D., Cadenhead, K., Cornblatt, B., Woods, S. W., Addington, J., Walker, E., et al. (2008). Prediction of psychosis in youth at high clinical risk: a multisite longitudinal study in North America. Archives of General Psychiatry, 65(1), 28-37.

Cannon, T. D., van Erp, T. G., Rosso, I. M., Huttunen, M., Lonnqvist, J., Pirkola, T., et al. (2002). Fetal hypoxia and structural brain abnormalities in schizophrenic patients, their siblings, and controls. Archives of General Psychiatry, 59(1), 35-41.

Carter, C. S., Robertson, L. C., \& Nordahl, T. E. (1992). Abnormal processing of irrelevant information in chronic schizophrenia: selective enhancement of Stroop facilitation. Psychiatry Research, 41(2), 137-146.

Carter, C. S., Robertson, L. C., Nordahl, T. E., Chaderjian, M., \& Oshora-Celaya, L. (1996). Perceptual and attentional asymmetries in schizophrenia: further evidence for a left hemisphere deficit. Psychiatry Research, 62(2), 111-119.

Casey, B. J., Giedd, J. N., \& Thomas, K. M. (2000). Structural and functional brain development and its relation to cognitive development. Biological Psychology, 54(1-3), 241-257.

Chung, Y. S., Kang, D. H., Shin, N. Y., Yoo, S. Y., \& Kwon, J. S. (2008). Deficit of theory of mind in individuals at ultra-high-risk for schizophrenia. Schizophrenia Research, 99(1-3), 111-118.

Clare, L., McKenna, P. J., Mortimer, A. M., \& Baddeley, A. D. (1993). Memory in schizophrenia: what is impaired and what is preserved? Neuropsychologia, 31(11), 1225-1241.

Combs, D. R., Adams, S. D., Penn, D. L., Roberts, D., Tiegreen, J., \& Stem, P. (2007). Social Cognition and Interaction Training (SCIT) for inpatients with schizophrenia spectrum disorders: preliminary findings. Schizophrenia Research, 91(1-3), 112-116.

Condray, R., van Kammen, D. P., Steinhauer, S. R., Kasparek, A., \& Yao, J. K. (1995). Language comprehension in schizophrenia: trait or state indicator? Biological Psychiatry, 38(5), 287-296.

Cornblatt, B. A., Auther, A. M., Niendam, T., Smith, C. W., Zinberg, J., Bearden, C. E., et al. (2007). Preliminary findings for two new measures of social and role functioning in the prodromal phase of schizophrenia. Schizophrenia Bulletin, 33(3), 688-702.

Cornblatt, B. A., Lenzenweger, M. F., \& Erlenmeyer-Kimling, L. (1989). The continuous performance test, identical pairs version: II. Contrasting attentional profiles in schizophrenic and depressed patients. Psychiatry Research, 29(1), 65-85.

Cornblatt, B. A., Obuchowski, M., Roberts, S., Pollack, S., \& Erlenmeyer-Kimling, L. (1999). Cognitive and behavioral precursors of schizophrenia. Development and Psychopathology, 11 (3), 487-508.

Corrigan, P. W., \& Toomey, R. (1995). Interpersonal problem solving and information processing in schizophrenia. Schizophrenia Bulletin, 21(3), 395-403.

Cosway, R., Byrne, M., Clafferty, R., Hodges, A., Grant, E., Abukmeil, S. S., et al. (2000). Neuropsychological change in young people at high risk for schizophrenia: results from the first two neuropsychological assessments of the Edinburgh High Risk Study. Psychological Medicine, 30(5), 1111-1121.

Couture, S. M., Penn, D. L., \& Roberts, D. L. (2006). The functional significance of social cognition in schizophrenia: a review. Schizophrenia Bulletin, 32(Suppl 1), S44-63.

Davis, K. L., Stewart, D. G., Friedman, J. I., Buchsbaum, M., Harvey, P. D., Hof, P. R., et al. (2003). White matter changes in schizophrenia: evidence for myelin-related dysfunction. Archives of General Psychiatry, 60(5), 443-456.

Docherty, N., DeRosa, M., \& Andreasen, N. C. (1996). Communication disturbances in schizophrenia and mania. Archives of General Psychiatry, 53(4), 358-364.

Docherty, N., Schnur, M., \& Harvey, P. D. (1988). Reference performance and positive and negative thought disorder: a follow-up study of manics and schizophrenics. Journal of Abnormal Psychology, 97(4), 437-442.

Eack, S. M., Greeno, C. G., Pogue-Geile, M. F., Newhill, C. E., Hogarty, G. E., \& Keshavan, M. S. (2008). Assessing SocialCognitive Deficits in Schizophrenia With the Mayer-SaloveyCaruso Emotional Intelligence Test. Schizophrenia Bulletin, doi:10.1093/schbul/sbn1091.

Eastvold, A. D., Heaton, R. K., \& Cadenhead, K. S. (2007). Neurocognitive deficits in the (putative) prodrome and first episode of psychosis. Schizophrenia Research, 93(1-3), 266277.

Erlenmeyer-Kimling, L., Rock, D., Roberts, S. A., Janal, M., Kestenbaum, C., Cornblatt, B., et al. (2000). Attention, memory, and motor skills as childhood predictors of schizophrenia-related psychoses: the New York high-risk project. American Journal of Psychiatry, 157(9), 1416-1422.

Feinberg, I. (1982). Schizophrenia: caused by a fault in programmed synaptic elimination during adolescence? Journal of Psychiatric Reseach, 17(4), 319-334.

Fornito, A., Yung, A. R., Wood, S. J., Phillips, L. J., Nelson, B., Cotton, S., et al. (2008). Anatomic abnormalities of the anterior cingulate cortex before psychosis onset: an MRI study of ultra-high-risk individuals. Biological Psychiatry, 64 (9), 758-765.

Francey, S. M., Jackson, H. J., Phillips, L. J., Wood, S. J., Yung, A. R., \& McGorry, P. D. (2005). Sustained attention in young people at high risk of psychosis does not predict transition to psychosis. Schizophrenia Research, 79(1), 127-136.

Friston, K. J. (1998). The disconnection hypothesis. Schizophrenia Research, 30(2), 115-125.

Frith, C. D. (1992). The cognitive neuropsychology of schizophrenia. Hove, UK: Lawrence Erlbaum Associates.

Frith, C. D., \& Frith, U. (2007). Social cognition in humans. Current Biology, 17(16), R724-732.

Frommann, N., Streit, M., \& Wolwer, W. (2003). Remediation of facial affect recognition impairments in patients with schizophrenia: a new training program. Psychiatry Research, 117(3), 281284.

Fuller, R., Nopoulos, P., Arndt, S., O’Leary, D., Ho, B. C., \& Andreasen, N. C. (2002). Longitudinal assessment of premorbid cognitive functioning in patients with schizophrenia through examination of standardized scholastic test performance. American Journal of Psychiatry, 159(7), 1183-1189.

Giedd, J. N., Blumenthal, J., Jeffries, N. O., Castellanos, F. X., Liu, H., Zijdenbos, A., et al. (1999). Brain development during childhood and adolescence: a longitudinal MRI study. Nature Neuroscience, 2(10), 861-863.

Glahn, D. C., Cannon, T. D., Gur, R. E., Ragland, J. D., \& Gur, R. C. (2000). Working memory constrains abstraction in schizophrenia. Biological Psychiatry, 47(1), 34-42.

Gogtay, N., Giedd, J. N., Lusk, L., Hayashi, K. M., Greenstein, D., Vaituzis, A. C., et al. (2004). Dynamic mapping of human cortical development during childhood through early adulthood. Proceedings of the National Academy of Sciences of the United States of America, 101(21), 8174-8179.

Gold, J. M. (2004). Cognitive deficits as treatment targets in schizophrenia. Schizophrenia Research, 72(1), 21-28.

Gold, J. M., Carpenter, C., Randolph, C., Goldberg, T. E., \& Weinberger, D. R. (1997). Auditory working memory and 
Wisconsin Card Sorting Test performance in schizophrenia. Archives of General Psychiatry, 54(2), 159-165.

Green, M. F. (1996). What are the functional consequences of neurocognitive deficits in schizophrenia? American Journal of Psychiatry, 153(3), 321-330.

Green, M. F., Kern, R. S., Braff, D. L., \& Mintz, J. (2000). Neurocognitive deficits and functional outcome in schizophrenia: are we measuring the "right stuff"? Schizophrenia Bulletin, 26(1), $119-136$.

Green, M. F., \& Nuechterlein, K. H. (2004). The MATRICS initiative: developing a consensus cognitive battery for clinical trials. Schizophrenia Research, 72(1), 1-3.

Gschwandtner, U., Aston, J., Borgwardt, S., Drewe, M., Feinendegen, C., Lacher, D., et al. (2003). Neuropsychological and neurophysiological findings in individuals suspected to be at risk for schizophrenia: preliminary results from the Basel early detection of psychosis study - Fruherkennung von Psychosen (FEPSY). Acta Psychiatr Scand, 108(2), 152-155.

Gschwandtner, U., Pfluger, M., Aston, J., Borgwardt, S., Drewe, M., Stieglitz, R. D., et al. (2006). Fine motor function and neuropsychological deficits in individuals at risk for schizophrenia. Eur Arch Psychiatry Clin Neurosci, 256(4), 201-206.

Hambrecht, M., Lammertink, M., Klosterkotter, J., Matuschek, E., \& Pukrop, R. (2002). Subjective and objective neuropsychological abnormalities in a psychosis prodrome clinic. British Journal of Psychiatry Supplement, 43, s30-37.

Happe, F. G. (1994). An advanced test of theory of mind: understanding of story characters' thoughts and feelings by able autistic, mentally handicapped, and normal children and adults. $J$ Autism Dev Disord, 24(2), 129-154.

Harvey, P. D. (1983). Speech competence in manic and schizophrenic psychoses: the association between clinically rated thought disorder and cohesion and reference performance. J Abnorm Psychol, 92(3), 368-377.

Hawkins, K. A., Addington, J., Keefe, R. S., Christensen, B., Perkins, D. O., Zipurksy, R., et al. (2004). Neuropsychological status of subjects at high risk for a first episode of psychosis. Schizophrenia Research, 67(2-3), 115-122.

Ho, B. C., Andreasen, N. C., Nopoulos, P., Arndt, S., Magnotta, V., \& Flaum, M. (2003). Progressive structural brain abnormalities and their relationship to clinical outcome: a longitudinal magnetic resonance imaging study early in schizophrenia. Archives of General Psychiatry, 60(6), 585-594.

Holmen, A., Juuhl-Langseth, M., Thormodsen, R., Melle, I., \& Rund, B. R. (2009). Neuropsychological Profile in Early-Onset Schizophrenia-Spectrum Disorders: Measured With the MATRICS Battery. Schizophr Bull.

Holthausen, E. A., Wiersma, D., Sitskoorn, M. M., Dingemans, P. M., Schene, A. H., \& van den Bosch, R. J. (2003). Long-term memory deficits in schizophrenia: primary or secondary dysfunction? Neuropsychology, 17(4), 539-547.

Honey, G. D., Pomarol-Clotet, E., Corlett, P. R., Honey, R. A., McKenna, P. J., Bullmore, E. T., et al. (2005). Functional dysconnectivity in schizophrenia associated with attentional modulation of motor function. Brain, 128(Pt 11), 2597-2611.

Horan, W. P., Kern, R. S., Shokat-Fadai, K., Sergi, M. J., Wynn, J. K., \& Green, M. F. (2009). Social cognitive skills training in schizophrenia: An initial efficacy study of stabilized outpatients. Schizophrenia Research, 107(1), 47-54.

Hurlemann, R., Matusch, A., Kuhn, K. U., Berning, J., Elmenhorst, D., Winz, O., et al. (2008). 5-HT2A receptor density is decreased in the at-risk mental state. Psychopharmacology (Berl), 195(4), 579-590.

Ihnen, G. H., Penn, D. L., Corrigan, P. W., \& Martin, J. (1998). Social perception and social skill in schizophrenia. Psychiatry Research, $80(3), 275-286$.
Jafri, M. J., Pearlson, G. D., Stevens, M., \& Calhoun, V. D. (2008). A method for functional network connectivity among spatially independent resting-state components in schizophrenia. Neuroimage, 39(4), 1666-1681.

Javitt, D. C., \& Zukin, S. R. (1991). Recent advances in the phencyclidine model of schizophrenia. American Journal of Psychiatry, 148(10), 1301-1308.

Job, D. E., Whalley, H. C., McIntosh, A. M., Owens, D. G., Johnstone, E. C., \& Lawrie, S. M. (2006). Grey matter changes can improve the prediction of schizophrenia in subjects at high risk. BMC Medical, 4, 29.

Jones, P., Rodgers, B., Murray, R., \& Marmot, M. (1994). Child development risk factors for adult schizophrenia in the British 1946 birth cohort. Lancet, 344(8934), 1398-1402.

Karlsgodt, K. H., Niendam, T. A., Bearden, C. E., \& Cannon, T. D. (2009). White Matter Integrity and Prediction of Social and Role Functioning in Subjects at Ultra-High Risk for Psychosis. Biol Psychiatry. doi:10.1016/j.biopsych.2009.03.013

Karlsgodt, K. H., Sun, D., Jimenez, A. M., Lutkenhoff, E. S., Willhite, R., van Erp, T. G., et al. (2008). Developmental disruptions in neural connectivity in the pathophysiology of schizophrenia. Development and Psychopathology, 20(4), 1297-1327.

Kee, K. S., Green, M. F., Mintz, J., \& Brekke, J. S. (2003). Is emotion processing a predictor of functional outcome in schizophrenia? Schizophrenia Bulletin, 29(3), 487-497.

Kee, K. S., Horan, W. P., Salovey, P., Kern, R. S., Sergi, M. J., Fiske, A. P., et al. (2009). Emotional intelligence in schizophrenia. Schizophrenia Research, 107(1), 61-68.

Keefe, R. S., Perkins, D. O., Gu, H., Zipursky, R. B., Christensen, B. K., \& Lieberman, J. A. (2006). A longitudinal study of neurocognitive function in individuals at-risk for psychosis. Schizophrenia Research, 88(1-3), 26-35.

Keefe, R. S., Roitman, S. E., Harvey, P. D., Blum, C. S., DuPre, R. L., Prieto, D. M., et al. (1995). A pen-and-paper human analogue of a monkey prefrontal cortex activation task: spatial working memory in patients with schizophrenia. Schizophrenia Research, 17(1), 25-33.

Kerr, S. L., \& Neale, J. M. (1993). Emotion perception in schizophrenia: specific deficit or further evidence of generalized poor performance? Journal of Abnormal Psychology, 102(2), 312-318.

Kim, D. I., Manoach, D. S., Mathalon, D. H., Turner, J. A., Mannell, M., Brown, G. G., et al. (2009). Dysregulation of working memory and default-mode networks in schizophrenia using independent component analysis, an fBIRN and MCIC study. Hum Brain Mapp.

Kinderman, P., \& Bentall, R. P. (1996). A new measure of causal locus: the internal, personal, and situational attributions questionnaire. Personality and Individual Differences, 20, 261-264.

Klosterkotter, J., Hellmich, M., Steinmeyer, E. M., \& Schultze-Lutter, F. (2001). Diagnosing schizophrenia in the initial prodromal phase. Archives of General Psychiatry, 58(2), 158-164.

Kraeplin, E. (1896). Psychiatric. (A. R. Defendorf, Trans.). New York. Lappin, J. M., Dazzan, P., Morgan, K., Morgan, C., Chitnis, X., Suckling, J., et al. (2007). Duration of prodromal phase and severity of volumetric abnormalities in first-episode psychosis. British Journal of Psychiatry Supplement, 51, s123-127.

Larsen, T. K., McGlashan, T. H., \& Moe, L. C. (1996). First-episode schizophrenia: I. Early course parameters. Schizophrenia Bulletin, 22(2), 241-256.

Lencz, T., Smith, C., McLaughlin, D., Auther, A., Nakayama, E., Hovey, L., et al. (2006). Generalized and specific neurocognitive deficits in prodromal schizophrenia. Biological Psychiatry, 59(9), 863-871.

Liang, M., Zhou, Y., Jiang, T., Liu, Z., Tian, L., Liu, H., et al. (2006). Widespread functional disconnectivity in schizophrenia with 
resting-state functional magnetic resonance imaging. Neuroreport, 17(2), 209-213.

Lieberman, J., Chakos, M., Wu, H., Alvir, J., Hoffman, E., Robinson, D., et al. (2001). Longitudinal study of brain morphology in first episode schizophrenia. Biological Psychiatry, 49(6), 487-499.

Liu, Y., Liang, M., Zhou, Y., He, Y., Hao, Y., Song, M., et al. (2008). Disrupted small-world networks in schizophrenia. Brain, 131(Pt 4), 945-961.

Malla, A., \& Payne, J. (2005). First-episode psychosis: psychopathology, quality of life, and functional outcome. Schizophrenia Bulletin, 31(3), 650-671.

Marshall, M., Lewis, S., Lockwood, A., Drake, R., Jones, P., \& Croudace, T. (2005). Association between duration of untreated psychosis and outcome in cohorts of first-episode patients: a systematic review. Archives of General Psychiatry, 62(9), 975983.

Martin, J. A., \& Penn, D. L. (2002). Attributional style in schizophrenia: an investigation in outpatients with and without persecutory delusions. Schizophrenia Bulletin, 28(1), 131-141.

Mayer, J. D., Salovey, P., Caruso, D. R., \& Sitarenios, G. (2003). Measuring emotional intelligence with the MSCEIT V2.0. Emotion, 3(1), 97-105.

McGlashan, T. H. (2001). Structured interview for prodromal syndromes (SIPS). New Haven: Yale University.

McGlashan, T. H., \& Hoffman, R. E. (2000). Schizophrenia as a disorder of developmentally reduced synaptic connectivity. Archives of General Psychiatry, 57(7), 637-648.

McGlashan, T. H., \& Johannessen, J. O. (1996). Early detection and intervention with schizophrenia: rationale. Schizophrenia Bulletin, 22(2), 201-222.

McGlashan, T. H., Zipursky, R. B., Perkins, D., Addington, J., Miller, T., Woods, S. W., et al. (2006). Randomized, double-blind trial of olanzapine versus placebo in patients prodromally symptomatic for psychosis. American Journal of Psychiatry, 163(5), 790-799.

McGorry, P. D., Yung, A. R., Phillips, L. J., Yuen, H. P., Francey, S., Cosgrave, E. M., et al. (2002). Randomized controlled trial of interventions designed to reduce the risk of progression to firstepisode psychosis in a clinical sample with subthreshold symptoms. Archives of General Psychiatry, 59(10), 921-928.

McGurk, S. R., Twamley, E. W., Sitzer, D. I., McHugo, G. J., \& Mueser, K. T. (2007). A meta-analysis of cognitive remediation in schizophrenia. American Journal of Psychiatry, 164(12), 1791-1802.

McKibbin, C. L., Brekke, J. S., Sires, D., Jeste, D. V., \& Patterson, T. L. (2004). Direct assessment of functional abilities: relevance to persons with schizophrenia. Schizophrenia Research, 72(1), 5367.

Meyer, S. E., Bearden, C. E., Lux, S. R., Gordon, J. L., Johnson, J. K., O'Brien, M. P., et al. (2005). The psychosis prodrome in adolescent patients viewed through the lens of DSM-IV. Journal of Child and Adolescent Psychopharmacology, 15(3), 434-451.

Milev, P., Ho, B. C., Arndt, S., Nopoulos, P., \& Andreasen, N. C. (2003). Initial magnetic resonance imaging volumetric brain measurements and outcome in schizophrenia: a prospective longitudinal study with 5-year follow-up. Biological Psychiatry, 54(6), 608-615.

Miller, T. J., McGlashan, T. H., Rosen, J. L., Somjee, L., Markovich, P. J., Stein, K., et al. (2002). Prospective diagnosis of the initial prodrome for schizophrenia based on the Structured Interview for Prodromal Syndromes: preliminary evidence of interrater reliability and predictive validity. American Journal of Psychiatry, 159(5), 863-865.

Miller, T. J., McGlashan, T. H., Woods, S. W., Stein, K., Driesen, N., Corcoran, C. M., et al. (1999). Symptom assessment in schizophrenic prodromal states. Psychiatric Quarterly, 70(4), $273-287$.
Mirsky, A. F. (1969). Neuropsychological bases of schizophrenia. Annual Review of Psychology, 20, 321-348.

Mizrahi, R., Addington, J., Remington, G., \& Kapur, S. (2008). Attribution style as a factor in psychosis and symptom resolution. Schizophrenia Research, 104(1-3), 220-227.

Morice, R., \& McNicol, D. (1985). The comprehension and production of complex syntax in schizophrenia. Cortex, 21(4), 567-580.

Nieman, D., Becker, H., van de Fliert, R., Plat, N., Bour, L., Koelman, H., et al. (2007). Antisaccade task performance in patients at ultra high risk for developing psychosis. Schizophrenia Research, 95 (1-3), 54-60.

Niendam, T. A., Bearden, C. E., Johnson, J. K., McKinley, M., Loewy, R., O'Brien, M., et al. (2006). Neurocognitive performance and functional disability in the psychosis prodrome. Schizophrenia Research, 84(1), 100-111.

Niendam, T. A., Bearden, C. E., Rosso, I. M., Sanchez, L. E., Hadley, T., Nuechterlein, K. H., et al. (2003). A prospective study of childhood neurocognitive functioning in schizophrenic patients and their siblings. American Journal Psychiatry, 160(11), 2060 2062.

Niendam, T. A., Bearden, C. E., Zinberg, J., Johnson, J. K., O’Brien, M., \& Cannon, T. D. (2007). The course of neurocognition and social functioning in individuals at ultra high risk for psychosis. Schizophrenia Bulletin, 33(3), 772-781.

Nuechterlein, K. H., \& Dawson, M. E. (1984). Information processing and attentional functioning in the developmental course of schizophrenic disorders. Schizophrenia Bulletin, 10(2), 160-203.

Pantelis, C., Velakoulis, D., McGorry, P. D., Wood, S. J., Suckling, J., Phillips, L. J., et al. (2003). Neuroanatomical abnormalities before and after onset of psychosis: a cross-sectional and longitudinal MRI comparison. Lancet, 361(9354), 281-288.

Pantelis, C., Yucel, M., Wood, S. J., Velakoulis, D., Sun, D., Berger, G., et al. (2005). Structural brain imaging evidence for multiple pathological processes at different stages of brain development in schizophrenia. Schizophrenia Bulletin, 31(3), 672-696.

Park, S., \& Holzman, P. S. (1992). Schizophrenics show spatial working memory deficits. Archives of General Psychiatry, 49 (12), 975-982.

Paus, T., Collins, D. L., Evans, A. C., Leonard, G., Pike, B., \& Zijdenbos, A. (2001). Maturation of white matter in the human brain: a review of magnetic resonance studies. Brain Research Bulletin, 54(3), 255-266.

Penn, D. L., Corrigan, P. W., Bentall, R. P., Racenstein, J. M., \& Newman, L. (1997). Social cognition in schizophrenia. Psychological Bulletin, 121(1), 114-132.

Penn, D. L., Ritchie, M., Francis, J., Combs, D., \& Martin, J. (2002). Social perception in schizophrenia: the role of context. Psychiatry Research, 109(2), 149-159.

Penn, D. L., Roberts, D. L., Combs, D., \& Sterne, A. (2007). Best practices: The development of the Social Cognition and Interaction Training program for schizophrenia spectrum disorders. Psychiatric Service, 58(4), 449-451.

Perkins, D. O., Gu, H., Boteva, K., \& Lieberman, J. A. (2005). Relationship between duration of untreated psychosis and outcome in first-episode schizophrenia: a critical review and meta-analysis. American Journal of Psychiatry, 162(10), 1785-1804.

Perner, J., \& Wimmer, H. (1985). 'John thinks that Mary thinks that...': attribution of second-order false beliefs by 5 - to 10 -year old children. Journal of Experimental Child Psychology, 39, 437-471.

Peters, B. D., Schmitz, N., Dingemans, P. M., van Amelsvoort, T. A., Linszen, D. H., de Haan, L., et al. (2009). Preliminary evidence for reduced frontal white matter integrity in subjects at ultra-highrisk for psychosis. Schizophrenia Research, 111(1-3), 192-193. 
Phillips, L. J., Velakoulis, D., Pantelis, C., Wood, S., Yuen, H. P., Yung, A. R., et al. (2002). Non-reduction in hippocampal volume is associated with higher risk of psychosis. Schizophrenia Research, 58(2-3), 145-158.

Pickup, G. J., \& Frith, C. D. (2001). Theory of mind impairments in schizophrenia: symptomatology, severity and specificity. Psychological Medicine, 31(2), 207-220.

Pijnenborg, G. H., Withaar, F. K., Evans, J. J., RJ, V. D. B., Timmerman, M. E., \& Brouwer, W. H. (2009). The predictive value of measures of social cognition for community functioning in schizophrenia: Implications for neuropsychological assessment. J Int Neuropsychol Soc, 1-9.

Pinkham, A. E., \& Penn, D. L. (2006). Neurocognitive and social cognitive predictors of interpersonal skill in schizophrenia. Psychiatry Research, 143(2-3), 167-178.

Pinkham, A. E., Penn, D. L., Perkins, D. O., Graham, K. A., \& Siegel, M. (2007). Emotion perception and social skill over the course of psychosis: a comparison of individuals "at-risk" for psychosis and individuals with early and chronic schizophrenia spectrum illness. Cogn Neuropsychiatry, 12(3), 198-212.

Prasad, K. M., Sahni, S. D., Rohm, B. R., \& Keshavan, M. S. (2005). Dorsolateral prefrontal cortex morphology and short-term outcome in first-episode schizophrenia. Psychiatry Research, 140 (2), 147-155.

Pukrop, R., Ruhrmann, S., Schultze-Lutter, F., Bechdolf, A., Brockhaus-Dumke, A., \& Klosterkotter, J. (2007). Neurocognitive indicators for a conversion to psychosis: comparison of patients in a potentially initial prodromal state who did or did not convert to a psychosis. Schizophrenia Research, 92(1-3), 116-125.

Pukrop, R., Schultze-Lutter, F., Ruhrmann, S., Brockhaus-Dumke, A., Tendolkar, I., Bechdolf, A., et al. (2006). Neurocognitive functioning in subjects at risk for a first episode of psychosis compared with first- and multiple-episode schizophrenia. Journal of Clinical and Experimental Neuropsychology, 28(8), 1388-1407.

Ranganath, C., Minzenberg, M. J., \& Ragland, J. D. (2008). The cognitive neuroscience of memory function and dysfunction in schizophrenia. Biological Psychiatry, 64(1), 18-25.

Roncone, R., Falloon, I. R., Mazza, M., De Risio, A., Pollice, R., Necozione, S., et al. (2002). Is theory of mind in schizophrenia more strongly associated with clinical and social functioning than with neurocognitive deficits? Psychopathology, 35(5), 280-288.

Rosenthal, R., Hall, J. A., DiMatteo, M. R., Rogers, P. L., \& Archer, D. (1979). Profile of nonverbal sensitivity. Baltimore, MD: Johns Hopkins University Press.

Russell, A. J., Munro, J. C., Jones, P. B., Hemsley, D. R., \& Murray, R. M. (1997). Schizophrenia and the myth of intellectual decline. American Journal of Psychiatry, 154(5), 635-639.

Saykin, A. J., Gur, R. C., Gur, R. E., Mozley, P. D., Mozley, L. H., Resnick, S. M., et al. (1991). Neuropsychological function in schizophrenia. Selective impairment in memory and learning. Archives of General Psychiatry, 48(7), 618-624.

Schenkel, L. S., Spaulding, W. D., \& Silverstein, S. M. (2005). Poor premorbid social functioning and theory of mind deficit in schizophrenia: evidence of reduced context processing? Journal of Psychiatric Research, 39(5), 499-508.

Schlosser, R., Gesierich, T., Kaufmann, B., Vucurevic, G., Hunsche, S., Gawehn, J., et al. (2003). Altered effective connectivity during working memory performance in schizophrenia: a study with fMRI and structural equation modeling. Neuroimage, 19(3), 751-763.

Schwartz, B. L., Rosse, R. B., \& Deutsch, S. I. (1992). Toward a neuropsychology of memory in schizophrenia. Psychopharmacology Bulletin, 28(4), 341-351.

Selemon, L. D., \& Goldman-Rakic, P. S. (1999). The reduced neuropil hypothesis: a circuit based model of schizophrenia. Biological Psychiatry, 45(1), 17-25.
Sergi, M. J., Fiske, A. P., Horan, W. P., Kern, R. S., Kee, K. S., Subotnik, K. L., et al. (2009). Development of a measure of relationship perception in schizophrenia. Psychiatry Res.

Sergi, M. J., Rassovsky, Y., Nuechterlein, K. H., \& Green, M. F. (2006). Social perception as a mediator of the influence of early visual processing on functional status in schizophrenia. American Journal of Psychiatry, 163(3), 448-454.

Sergi, M. J., Rassovsky, Y., Widmark, C., Reist, C., Erhart, S., Braff, D. L., et al. (2007). Social cognition in schizophrenia: relationships with neurocognition and negative symptoms. Schizophrenia Research, 90(1-3), 316-324.

Silverstein, S., Uhlhaas, P. J., Essex, B., Halpin, S., Schall, U., \& Carr, V. (2006). Perceptual organization in first episode schizophrenia and ultra-high-risk states. Schizophrenia Research, 83(1), 41-52.

Simon, A. E., Cattapan-Ludewig, K., Zmilacher, S., Arbach, D., Gruber, K., Dvorsky, D. N., et al. (2007). Cognitive functioning in the schizophrenia prodrome. Schizophrenia Bulletin, 33(3), 761-771.

Smith, C. W., Park, S., \& Cornblatt, B. (2006). Spatial working memory deficits in adolescents at clinical high risk for schizophrenia. Schizophrenia Research, 81(2-3), 211-215.

Sugranyes, G., Flamarique, I., Parellada, E., Baeza, I., Goti, J., Fernandez-Egea, E., et al. (2009). Cannabis use and age of diagnosis of schizophrenia. Eur Psychiatry.

Sun, D., Phillips, L., Velakoulis, D., Yung, A., McGorry, P. D., Wood, S. J., et al. (2009). Progressive brain structural changes mapped as psychosis develops in 'at risk' individuals. Schizophrenia Research, 108(1-3), 85-92.

Sun, D., Stuart, G. W., Jenkinson, M., Wood, S. J., McGorry, P. D., Velakoulis, D., et al. (2008). Brain surface contraction mapped in first-episode schizophrenia: a longitudinal magnetic resonance imaging study. Mol Psychiatry, doi:10.1038/mp.2008.34.

Takahashi, T., Wood, S. J., Yung, A. R., Phillips, L. J., Soulsby, B., McGorry, P. D., et al. (2009). Insular cortex gray matter changes in individuals at ultra-high-risk of developing psychosis. Schizophrenia Research, 111(1-3), 94-102.

Tamlyn, D., McKenna, P. J., Mortimer, A. M., Lund, C. E., Hammond, S., \& Baddeley, A. D. (1992). Memory impairment in schizophrenia: its extent, affiliations and neuropsychological character. Psychological Medicine, 22(1), 101-115.

Toomey, R., Wallace, C. J., Corrigan, P. W., Schuldberg, D., \& Green, M. F. (1997). Social processing correlates of nonverbal social perception in schizophrenia. Psychiatry, 60(4), 292-300.

van Haren, N. E., Cahn, W., Hulshoff Pol, H. E., Schnack, H. G., Caspers, E., Lemstra, A., et al. (2003). Brain volumes as predictor of outcome in recent-onset schizophrenia: a multicenter MRI study. Schizophrenia Research, 64(1), 41-52.

Vauth, R., Rusch, N., Wirtz, M., \& Corrigan, P. W. (2004). Does social cognition influence the relation between neurocognitive deficits and vocational functioning in schizophrenia? Psychiatry Research, 128(2), 155-165.

Walterfang, M., McGuire, P. K., Yung, A. R., Phillips, L. J., Velakoulis, D., Wood, S. J., et al. (2008). White matter volume changes in people who develop psychosis. British Journal of Psychiatry, 193(3), 210-215.

Walterfang, M., Yung, A., Wood, A. G., Reutens, D. C., Phillips, L., Wood, S. J., et al. (2008). Corpus callosum shape alterations in individuals prior to the onset of psychosis. Schizophrenia Research, 103(1-3), 1-10.

Wimmer, H., \& Perner, J. (1983). Beliefs about beliefs: representation and constraining function of wrong beliefs in young children's understanding of deception. Cognition, 13(1), 103-128.

Witthaus, H., Brune, M., Kaufmann, C., Bohner, G., Ozgurdal, S., Gudlowski, Y., et al. (2008). White matter abnormalities in subjects at ultra high-risk for schizophrenia and first-episode schizophrenic patients. Schizophrenia Research, 102(1-3), 141-149. 
Wolwer, W., Frommann, N., Halfmann, S., Piaszek, A., Streit, M., \& Gaebel, W. (2005). Remediation of impairments in facial affect recognition in schizophrenia: efficacy and specificity of a new training program. Schizophrenia Research, 80(2-3), 295303.

Wood, G. K., Lipska, B. K., \& Weinberger, D. R. (1997). Behavioral changes in rats with early ventral hippocampal damage vary with age at damage. Developmental Brain Research, 101(1-2), 17-25.

Wood, S. J., Pantelis, C., Proffitt, T., Phillips, L. J., Stuart, G. W., Buchanan, J. A., et al. (2003). Spatial working memory ability is a marker of risk-for-psychosis. Psychological Medicine, 33(7), 1239-1247.

Wood, S. J., Pantelis, C., Velakoulis, D., Yucel, M., Fornito, A., \& McGorry, P. D. (2008). Progressive changes in the development toward schizophrenia: studies in subjects at increased symptomatic risk. Schizophrenia Bulletin, 34(2), 322-329.

Wood, S. J., Yucel, M., Velakoulis, D., Phillips, L. J., Yung, A. R., Brewer, W., et al. (2005). Hippocampal and anterior cingulate morphology in subjects at ultra-high-risk for psychosis: the role of family history of psychotic illness. Schizophrenia Research, 75 (2-3), 295-301.

Yoon, J. H., Minzenberg, M. J., Ursu, S., Walter, R., Wendelken, C., Ragland, J. D., et al. (2008). Association of dorsolateral prefrontal cortex dysfunction with disrupted coordinated brain activity in schizophrenia: relationship with impaired cognition, behavioral disorganization, and global function. American Journal of Psychiatry, 165(8), 1006-1014.

Yung, A. R., \& McGorry, P. D. (1996). The prodromal phase of firstepisode psychosis: past and current conceptualizations. Schizophrenia Bulletin, 22(2), 353-370.

Yung, A. R., Phillips, L. J., Yuen, H. P., Francey, S. M., McFarlane, C. A., Hallgren, M., et al. (2003). Psychosis prediction: 12-month follow up of a high-risk ("prodromal") group. Schizophrenia Research, 60(1), 21-32.

Yung, A. R., Yuen, H. P., McGorry, P. D., Phillips, L. J., Kelly, D., Dell'Olio, M., et al. (2005). Mapping the onset of psychosis: the Comprehensive Assessment of At-Risk Mental States. Australian and New Zealand Journal of Psychiatry, 39(11-12), 964-971. 